\title{
The Mediating Role of Depression in the Relationship Between Body Image Dissatisfaction and Cyberbullying Perpetration
}

\author{
Sabah Balta ${ }^{1} \cdot$ Emrah Emirtekin $^{2} \cdot$ Kagan Kircaburun $^{3} \cdot$ Mark D. Griffiths $^{4,5}$ (D)
}

Published online: 25 November 2019

(C) The Author(s) 2019

\begin{abstract}
Preliminary evidence suggests that psychopathological factors (e.g., depression) are associated with higher engagement in cyberbullying perpetration, and those with elevated body image dissatisfaction (BID) are more susceptible to depression. However, the possible impact of body image dissatisfaction (BID) on cyberbullying remains untested. The present study examined the direct and indirect relationships of BID with cyberbullying via depression among a sample of 507 university students (mean age, 21.37 years; range 18-44 years). $t$ tests showed that males had a higher prevalence of cyberbullying than females. Structural equation modeling indicated that BID was directly and indirectly associated with cyberbullying via depression among the total sample and males. However, BID was only indirectly related to cyberbullying via depression among females. Depression fully explained the relationship between BID and cyberbullying among females, although there were additional mediating factors between BID and cyberbullying among males. The findings are in accordance with theoretical models suggesting that individuals' personal characteristics including psychopathological factors are associated with cyberbullying. Furthermore, males attempt to cope with their body image-related psychopathology with more externalizing behaviors than females.
\end{abstract}

Keywords Cyberbullying · Body image · Body image dissatisfaction · Depression · Psychopathology

Mark D. Griffiths

mark.griffiths@ntu.ac.uk

Sabah Balta

sabah.balta@yasar.edu.tr

Emrah Emirtekin

emrah.emirtekin@yasar.edu.tr

Kagan Kircaburun

kircaburunkagan@gmail.com

Extended author information available on the last page of the article 
The rapid development in information and communication technology has brought both beneficial and harmful outcomes on individuals' lives. One such detrimental effect associated with internet technology is cyberbullying. Cyberbullying has been defined as "a set of behaviors performed through electronic or digital media by one individual or group of individuals who repeatedly communicate hostile or aggressive messages intended to inflict harm or discomfort on others" (Zych et al. 2019; p. 1). It has been reported that approximately $20-40 \%$ of youth are involved in cyberbullying and adversely affected from it (Tokunaga 2010). Many negative psychological consequences of cyberbullying have been reported among victims, including (i) elevated depression, anxiety, and stress; (ii) decreased selfesteem and self-worth; and (iii) increased probability of self-injury and suicidal ideation (Kowalski et al. 2014). Therefore, effective prevention and intervention strategies should be developed for cyberbullying by determining the factors that lead to it.

According to the General Aggression Model (Anderson and Bushman 2002), individual factors play an important role in aggressive behaviors by affecting decision-making processes. Mentally exhausted individuals are more likely to fail in controlling themselves when provoked (DeWall et al. 2011). To date, studies have consistently demonstrated that psychopathology has an exacerbating role on cyberbullying. More specifically, studies have identified several psychopathological symptoms that have a positive correlation with cyberbullying, including depression, phobic anxiety, internalizing and externalizing problems, interpersonal sensitivity, paranoia, and psychoticism (Guo 2016; Schenk et al. 2013). However, despite the growing body of literature, the potential role of body image dissatisfaction (BID) on cyberbullying has yet to be examined, even though those with lower BID are susceptible to engaging in aggressive behaviors (Salazar 2017). A cross-sectional study among males and females with multiple sclerosis indicated that fitness evaluation and body area dissatisfaction sub-dimensions of body image were related to elevated aggression (Farnam et al. 2017).

BID has been defined as "the discrepancy between identification of one's own figure (actual) and the figure one chose as the desirable self image (ideal)" (Forrest and Stuhldreher 2007, p. 18). The important part of BID is associated with weight-related problems especially among those who internalize sociocultural appearance standards (Matz et al. 2002). For instance, BID is observed among those with a high body mass index, such as African-American women who are overweight and seeking treatment for obesity (Johnson et al. 2019). For example, desire for thinness, feelings of being overweight, and fear of being too fat are among the important factors that contribute to BID among young females (McVey et al. 2004).

Furthermore, underweight and overweight male domestic violence offenders report increased BID (Shelton and Liljequist 2002). Given that BID is associated with higher addictive use of online activities in which cyberbullying occurs (Kircaburun et al. 2018a; Kircaburun et al. 2019a), BID has the potential to trigger aggressiveness for some individuals especially in online contexts. Those individuals who are more disturbed with their physical appearance are prone to spend excessive time on the internet, social media, gaming, and their smartphones (Emirtekin et al. 2019; Kircaburun et al. 2019b; Koronczai et al. 2013), which facilitates an elevated risk for engaging in anti-social online behaviors such as cyberbullying (Kircaburun et al. 2018b). Considering the highly prevalent use of social media among Turkish emerging adults (Kircaburun et al. 2018a), this overlap between BID and aggression was also expected to occur among Turkish participants.

Furthermore, psychopathological problems such as BID can make individuals susceptible to having higher levels of aggression, which is the primary predictor of cyberbullying (Tosuntaş, Balta, 
Emirtekin, Kircaburun, \& Griffiths, 2018). For instance, BID has been shown to be related to increased physical and verbal aggression among male domestic violence offenders (Shelton and Liljequist 2002). Aggression has also been positively correlated with body mass index among female students (Gallup and Wilson 2009). It may be that those with increased BID tend to reflect their inner unrest and irritation related to their disturbance with themselves by bullying others in online contexts where they perceive they can behave without facing any consequences of their deviant behaviors. Considering that online communication tools have become self-expression mediums for those who have trouble in real life (Ozden and Icellioglu 2014), it can be argued that those with higher BID might try to find comfort in expressing their inner unrest and making others feel miserable in virtual worlds (Tosuntaş et al. 2018).

BID is an important issue that threatens psychological health of both young men and women (Ackard et al. 2007). For instance, BID has been found to co-occur with and/or exacerbate other psychopathological symptoms such as depression (Paxton et al. 2006). For example, those with higher levels of BID have more symptoms of depression than others who do not have body dissatisfaction (Contreras-Valdez et al. 2016). This may be because high self-consciousness is associated with higher depression and those with more BID tend to have an impaired self-esteem when self-worth is overly based on physical appearance (Brechan \& Kvalem, 2015). Furthermore, elevated symptoms of depression are related to higher engagement in cyberbullying. Depressed individuals are susceptible to engaging in aggressive behaviors in online contexts due to their vulnerable and volatile psychological states (Tosuntaș et al. 2018). Given that depression leads to increased irritability and impulsivity, more symptoms of depression can lead to higher involvement in bullying others in online platforms (Chen et al. 2017). Therefore, in the present study it was hypothesized that depression would play a mediating role between BID and cyberbullying.

Consequently, the present study investigated the direct relationship between BID and cyberbullying, and the mediating role of depression between BID and cyberbullying. Gender differences were also examined because all study variables have been reported to differ among males and females. For instance, while males demonstrate cyberbullying more than females (Tosuntaş et al. 2018), females tend to have more symptoms of depression and BID compared with males (Morken et al. 2019; Nolen-Hoeksema and Hilt 2013).

\section{Methods}

\section{Participants and Procedure}

A total of 507 university students, aged between 18 and 44 years $(M=21.37$ years, $\mathrm{SD}=2.70$, $54 \%$ female), participated in the study. Participants were recruited from Yaşar University (Turkey). An online survey was promoted in distance learning center online courses using the center's survey software platform. The survey was kept available for participation for 3 months in order for participants to be able to fill out the surveys when they had the time to do so. The platform did not allow multiple participation. The collected data were stored in the system and extracted from the platform as a Microsoft Excel file. All participants were informed about the details of the study and gave their informed consent. They were also informed that participation in the study was voluntary and anonymous and that they would not get any reward for 
completing the online survey. Before the collection of the data, necessary permissions for the study were taken from Yaşar University's ethics committee, and complied with the Helsinki declaration.

\section{Measures}

Cyberbullying Offending Scale The Turkish form (Kircaburun et al., 2019) of the unidimensional COS (Patchin and Hinduja 2015) was used to assess cyberbullying perpetration (CBP) in the past month. The scale comprises nine items (e.g., "I spread rumors about someone online") on a five-point Likert scale, ranging from "never" (1), "once" (2), "a few times" (3), "several times" (4) and "many times" (5). In order to label aggressive online behaviors as CB, the behavior had to have occurred more than once (Patchin and Hinduja 2015; Zsila et al. 2018). Therefore, the COS was used in a dichotomized structure via re-coding "never" and "once" as 0, and a "few times," "several times," and "many times" as 1 . In the present study, the dichotomized scale showed excellent internal consistency (Cronbach's $\alpha=.96$ ).

Short Depression-Happiness Scale The Turkish form (Kircaburun et al., 2018c) of the SDHS (Joseph et al. 2004) was used to assess depression. The Turkish form comprises two subscales (i.e., depression and happiness). The scale comprises six items (three items in each subscale) on a four-point Likert scale ranging from " $1=$ never" to " $4=$ often". In the present study, only the depression subscale was used (e.g., "I felt that life was meaningless"). The subscale showed very high internal consistency $(\alpha=.90)$.

Body Image Dissatisfaction Scale The Turkish form (Kircaburun et al. 2019a) of the BIDS was developed based on the Physical Appearance Self-Competence subscale of the Self-Perception Profile for Adolescents (Harter 2012) and comprises three items (e.g., "I am not pleased with my physical appearance," "I wish my physical appearance was different") scored on a four-point Likert scale ranging from " $1=$ absolutely disagree" to " $4=$ very true." Internal consistency was high in the present study $(\alpha=.85)$.

\section{Statistical analysis}

Frequency and descriptive statistics, Pearson correlations, $t$ tests, and structural equation modeling (SEM) were computed via using SPSS 23.0 and AMOS 23.0 software. Frequency and descriptive statistics were used to determine mean scores and standard deviations of the study variables. Pearson's correlation test was utilized to determine correlation coefficients among the study variables and $t$ tests were applied to determine gender differences concerning the study variables. Finally, structural equation modeling was applied to identify direct and indirect relationships between the study variables. The tested model was evaluated using goodness of fit criteria. Accordingly, root mean square residuals (RMSEA) and standardized root mean square residuals (SRMR) should be below .05, and comparative fit index (CFI) and goodness of fit index (GFI) should be above .95 for a good fit. RMSEA and SRMR lower than .08, and CFI and GFI higher than .90 are thresholds for acceptable fit (Hu and Bentler 1999). Total, direct, and indirect effects of the independent and mediator variables on the outcome variable were 
calculated via using bootstrapping method with $95 \%$ bias-corrected confidence intervals and 5000 bootstrap samples.

\section{Results}

Mean scores, standard deviations, and correlation coefficients among the total sample are presented in Table 1. Depression was moderately correlated with cyberbullying and BID whereas the correlation coefficient between BID and cyberbullying was small. Results of the $t$ tests (Table 2) showed that only cyberbullying scores significantly differed between males and females with males having higher cyberbullying scores $(t[505]=-2.16, p=.03)$. Furthermore, there were no significant differences in depression scores $(t[505]=.85, p=.39)$ or BID scores $(t[505]=-1.14, p=.25)$. In order to test the hypothesized model (see Fig. 1), SEM was applied with the total sample, females only, and males only. Results demonstrated that all three mediation models (Fig. 2) with total sample $\left(\chi^{2} / \mathrm{df}=3.22\right.$, RMSEA $=.07(\mathrm{CI} 90 \%(.06, .08))$, SRMR $=.04, \mathrm{CFI}=.97, \mathrm{GFI}=.93)$, females $\left(\chi^{2} / \mathrm{df}=2.70, \mathrm{RMSEA}=.08(\mathrm{CI} 90 \%(.07, .09))\right.$, $\mathrm{SRMR}=.05, \mathrm{CFI}=.96, \mathrm{GFI}=.91)$, and males $\left(\chi^{2} / \mathrm{df}=2.65, \mathrm{RMSEA}=.08(\mathrm{CI} 90 \%(.07\right.$, $.10)$ ), $\mathrm{SRMR}=.05, \mathrm{CFI}=.96, \mathrm{GFI}=.88)$ indicated adequate-to-good fit to the data.

BID was directly $(\beta=.17, p<.01 ; 95 \% \mathrm{CI}(.04, .29))$ and indirectly $(\beta=.11, p<.001 ; 95 \%$ CI $(.06, .18))$ associated with cyberbullying via depression among the total sample, and directly $(\beta=.23, p<.01 ; 95 \%$ CI $(.06, .38))$ and indirectly $(\beta=.13, p<.01 ; 95 \%$ CI $(.06$, $.24)$ ) among males (Table 3 ). BID was indirectly related to cyberbullying via depression among females $(\beta=.11, p<.05 ; 95 \%$ CI $(.01, .22))$. Depression partially mediated the relationship between BID and cyberbullying in total sample and males, and fully in females. However, the total effect of BID on cyberbullying was small among the total sample $(\beta=.28$, $p<.001 ; 95 \% \mathrm{CI}(.19, .37))$ and females $(\beta=.19, p<.01 ; 95 \% \mathrm{CI}(.06, .32))$, and moderate among males $(\beta=.36, p<.001 ; 95 \% \mathrm{CI}(.23, .49))$. The tested structural equation model (Fig. 2 ) explained higher variance in cyberbullying among males $(17 \%)$ when compared with total sample $(11 \%)$ and females $(6 \%)$.

\section{Discussion}

The present study examined the direct and indirect relationship between BID and cyberbullying via depression among emerging adults in a university student sample. The most novel finding of the present study was that BID was directly associated with cyberbullying.

Table 1 Mean scores, standard deviations, and Pearson correlation coefficients of the study variables among total sample

\begin{tabular}{llll}
\hline & 1. & 2. & 3. \\
\hline 1. Cyberbullying perpetration & - & & \\
2. Depression & $.31^{* * *}$ & - & - \\
3. Body image dissatisfaction & $.28^{* * *}$ & $.48^{* * *}$ & 2.05 \\
$M$ & .16 & 2.25 & .90 \\
$S D$ & .31 & 1.00 & \\
\hline
\end{tabular}

$* * * p<.001$ 
Table 2 Comparison of the scores of study variables between females and males

\begin{tabular}{lllll}
\hline & $\begin{array}{l}\text { Female }(n=276) \\
\text { Mean (SD) }\end{array}$ & Male $(n=231)$ & $t$ test & Cohen's $d$ \\
\hline Cyberbullying perpetration & $.13(.29)$ & $.19(.34)$ & $-2.16^{*}$ & .02 \\
Body image dissatisfaction & $2.01(.88)$ & $2.10(.93)$ & -1.15 & .01 \\
Depression & $2.28(1.01)$ & $2.21(1.00)$ & .85 & .00 \\
\hline
\end{tabular}

$* p<.001$

Consequently, the present study is the first to demonstrate this association. Additionally, depression partially mediated this aforementioned relationship, although the results differed significantly among males and females. While depression fully explained the association between BID and cyberbullying among females, it was only a partial mediator among males.

BID has previously been reported to predict different types of aggressive behaviors (Shelton and Liljequist 2002). The present study showed that those with high BID engaged in repeated aggressive and harmful behaviors in online contexts. One possible explanation for this co-occurrence of BID and cyberbullying might be that body dissatisfaction is a psychopathological symptom that affects individuals' mental health and psychological well-being adversely (Ganem et al. 2009), making them mentally exhausted, leading to less control over their behaviors (DeWall et al. 2011). Furthermore, those with higher BID have been shown to experience higher victimization in traditional bullying (Wilson et al. 2013). It is well established that individuals who have been bullied in real life feel powerless and may try to compensate their negative feelings arising from being a bullying victim via bullying others in online contexts where they can feel powerful (Hinduja and Patchin 2008). Moreover, considering the highly prevalent use of social media among Turkish emerging adults and the facilitation of cyberbullying in social media platforms (Kircaburun et al. 2018a), this overlap between BID and cyberbullying among Turkish participants was in line with the expectations of the present study.

Findings also demonstrated that depression partially mediated the relationship between BID and cyberbullying. Higher BID was related to more symptoms of depression, and in turn, depression was associated with higher levels of cyberbullying. This is in line with the extant literature showing that depression is positively predicted by BID and it predicts higher cyberbullying (Blashill et al. 2016). Disturbance with body image can seriously lower an individual's self-esteem in which increased self-esteem is one of the most important protective factors against developing symptoms of depression (Koronczai et al. 2013). Individuals with

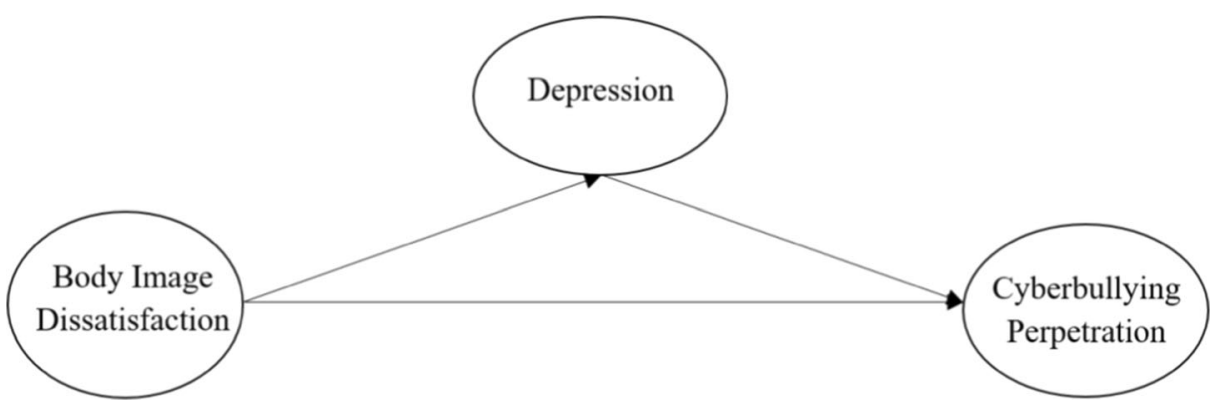

Fig. 1 Hypothesized model 


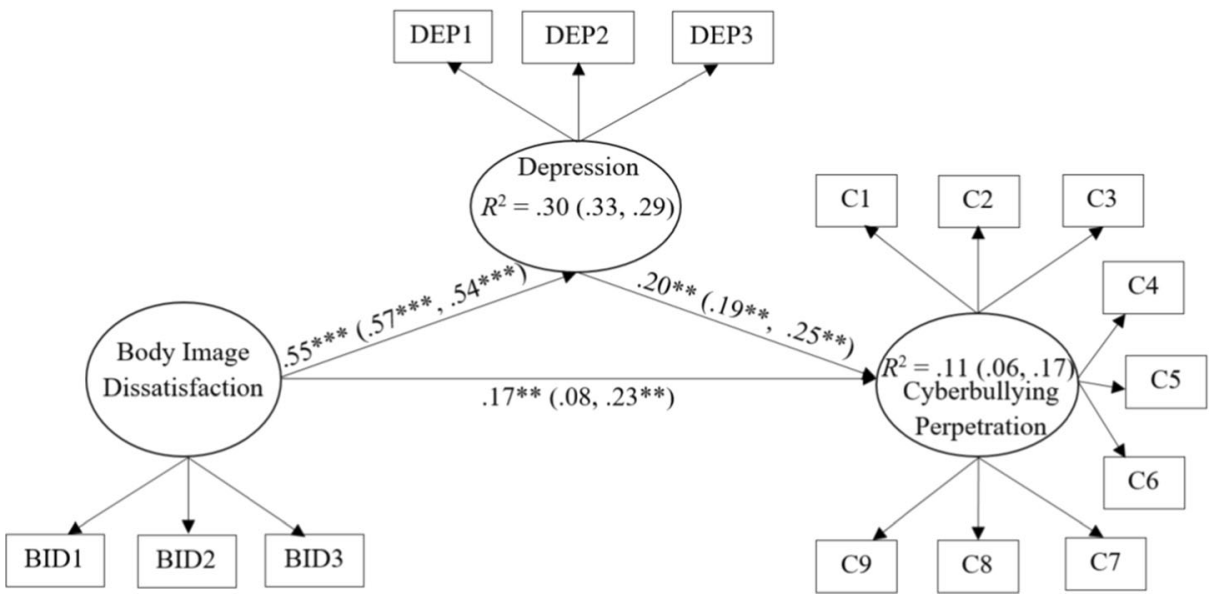

Fig. 2 Final model of the significant path coefficients between variables among total sample, females, and males. Latent variables are represented in the model by circles while observed variables are represented by rectangles. Path coefficients out of the brackets belong to total sample whereas values on the left side of brackets belong to females and the ones on the right belong to males. $* * p<.01, * * * p<.001$

higher BID are likely to be more vulnerable to experiencing negative emotions because of their decreased sense of self-worth (Brechan and Kvalem 2015). Similarly, depressed individuals are more susceptible to having decreased self-control and becoming emotionally unstable, as well as demonstrating externalizing problematic behaviors including verbal aggression and abuse toward others (Tosuntaş et al. 2018).

In terms of gender differences, there were slight differences in the aforementioned relationships between males and females. Depression was a full mediator between BID and cyberbullying among females whereas it played a partial mediating role among males. While females' cyberbullying can be explained particularly with BID-related depression, there were additional factors that can form a mediating pathway between BID and cyberbullying among men. It is known that (compared with males), females are less satisfied with their body image and suffer more adverse consequences related to this disturbance (Grogan 2016). However, it has also been established that while males are more prone to cope with their emotional frustration related to their psychological distress with externalizing behaviors (e.g., aggression), females tend to deal with them via internalizing behaviors (Blain et al. 2010). Consequently, the tested model explained higher variance of cyberbullying among males than females, which was expected.

Table 3 Standardized estimates of total, direct, and indirect effects among men and women

\begin{tabular}{|c|c|c|c|}
\hline \multirow[b]{2}{*}{ Pathways } & \multicolumn{3}{|l|}{ Effect (S.E.) } \\
\hline & Total sample & Men & Women \\
\hline $\mathrm{BID} \rightarrow \mathrm{CBP}$ (total effect) & $.28 * * *(.05)$ & $.36^{* * *}(.05)$ & $.19 * *(.03)$ \\
\hline $\mathrm{BID} \rightarrow \mathrm{CBP}$ (direct effect) & $.17 * *(.05)$ & $.23 * *(.04)$ & $.08(.03)$ \\
\hline $\mathrm{BID} \rightarrow$ Depression $\rightarrow \mathrm{CBP}$ (indirect effect) & $.11 * * *(.03)$ & $.13 * *(.04)$ & $.11 * * *(.04)$ \\
\hline
\end{tabular}

$B I D$, body image dissatisfaction; $C B P$, cyberbullying perpetration

$* p<.05, * * p<.01, * * * p<.001$ 
While taking the results of this study into account, several limitations should be considered. First, the sample was self-selected and comprised emerging adults from only one Turkish university, which limits the generalizability of the findings. Further studies are therefore needed among other Turkish populations and populations outside of Turkey. In terms of cross-cultural aspect of the study, it should be noted that cyberbullying and cyberbullyingrelated behaviors may vary among Turkish emerging adults when compared with some Western countries (Mura et al. 2011). It should be noted that cyberbullying prevalence, cyberbullying-related predictors and outcomes, and strategies for prevention and intervention for cyberbullying may differ according to culture, meaning that results of each study should be interpreted from its own cultural perspective (Baek and Bullock 2014). Second, the data were collected via self-report online surveys, which are susceptible to various response biases. Future studies should adopt more in-depth data collection methods (e.g., qualitative designs) in order to replicate and confirm the present findings. Third, the cross-sectional design prevents the drawing of conclusions in terms of causal relationships. Longitudinal studies are therefore needed to indicate causality and directions of the relationships examined in the present study.

Despite these limitations, the present study is the first to examine and demonstrate the direct relationship between BID and cyberbullying. The present findings suggest that higher dissatisfaction with body image can lead to greater cyberbullying perpetration. Moreover, depression explains the relationship between BID and cyberbullying fully among females and partially in males. In terms of cyberbullying intervention and prevention, health professionals and clinicians should focus on the underlying factors concerning body image dissatisfaction and depression in emerging adulthood. Cyberbullying prevention programs could benefit from specifically targeting body image dissatisfaction and attempting to reduce detrimental effects of depression-related cyberbullying through the reduction of the residual mental exhaustion from dissatisfaction with body image. The present study contributes to the existing anticyberbullying programs that have been shown to reduce cyberbullying perpetration only by approximately 10-15\% (Gaffney et al. 2019).

Acknowledgments Sources of funding are acknowledged.

Open Access This article is distributed under the terms of the Creative Commons Attribution 4.0 International License (http://creativecommons.org/licenses/by/4.0/), which permits unrestricted use, distribution, and reproduction in any medium, provided you give appropriate credit to the original author(s) and the source, provide a link to the Creative Commons license, and indicate if changes were made.

\section{Compliance with ethical standards}

Conflict of interest The authors declare that they have no conflict of interests.

Ethical Approval All procedures performed in this study involving human participants were in accordance with the ethical standards of University's Research Ethics Board and with the 1975 Helsinki Declaration.

Informed Consent Informed consent was obtained from all participants

Open Access This article is distributed under the terms of the Creative Commons Attribution 4.0 International License (http:/creativecommons.org/licenses/by/4.0/), which permits unrestricted use, distribution, and reproduction in any medium, provided you give appropriate credit to the original author(s) and the source, provide a link to the Creative Commons license, and indicate if changes were made. 


\section{References}

Ackard, D. M., Fulkerson, J. A., \& Neumark-Sztainer, D. (2007). Prevalence and utility of DSM-IV eating disorder diagnostic criteria among youth. International Journal of Eating Disorders, 40, 409-417.

Anderson, C. A., \& Bushman, B. J. (2002). Human aggression. Annual Review of Psychology, 53, $296-323$.

Baek, J., \& Bullock, L. M. (2014). Cyberbullying: a cross-cultural perspective. Emotional and Behavioural Difficulties, 19, 226-238.

Blain, L. M., Galovski, T. E., \& Robinson, T. (2010). Gender differences in recovery from posttraumatic stress disorder: a critical review. Aggression and Violent Behavior, 15, 463-474.

Blashill, A. J., Tomassilli, J., Biello, K., O’Cleirigh, C., Safren, S. A., \& Mayer, K. H. (2016). Body dissatisfaction among sexual minority men: psychological and sexual health outcomes. Archives of Sexual Behavior, 45, 1241-1247.

Brechan, I., \& Kvalem, I. L. (2015). Relationship between body dissatisfaction and disordered eating: mediating role of self-esteem and depression. Eating Behaviors, 17, 49-58.

Chen, L., Ho, S. S., \& Lwin, M. O. (2017). A meta-analysis of factors predicting cyberbullying perpetration and victimization: from the social cognitive and media effects approach. New Media \& Society, 19, 1194-1213.

Contreras-Valdez, J. A., Hernández-Guzmán, L., \& Freyre, M. Á. (2016). Body dissatisfaction, selfesteem, and depression in girls with obesity. Revista Mexicana de Trastornos Alimentarios, 7, $24-31$.

DeWall, C. N., Anderson, C. A., \& Bushman, B. J. (2011). The general aggression model: theoretical extensions to violence. Psychology of Violence, 1, 245-258.

Emirtekin, E., Balta, S., Sural, İ., Kircaburun, K., Griffiths, M. D., \& Billieux, J. (2019). The role of childhood emotional maltreatment and body image dissatisfaction in problematic smartphone use among adolescents. Psychiatry Research, 271, 634-639.

Farnam, A., Marashi, F., \& Sana'tnama, M. (2017). The relationship of body image with emotion regulation, stress, and aggression and their comparison between males and females with multiple sclerosis. Jundishapur Journal of Chronic Disease Care, 6, e13818.

Forrest, K. Y., \& Stuhldreher, W. L. (2007). Patterns and correlates of body image dissatisfaction and distortion among college students. American Journal of Health Studies, 22, 18-25.

Gaffney, H., Farrington, D. P., Espelage, D. L., \& Ttofi, M. M. (2019). Are cyberbullying intervention and prevention programs effective? A systematic and meta-analytical review. Aggression and Violent Behavior, $45,134-153$.

Gallup, A. C., \& Wilson, D. S. (2009). Body Mass Index (BMI) and peer aggression in adolescent females: an evolutionary perspective. Journal of Social, Evolutionary, and Cultural Psychology, 3, 356-371.

Ganem, P. A., de Heer, H., \& Morera, O. F. (2009). Does body dissatisfaction predict mental health outcomes in a sample of predominantly Hispanic college students? Personality and Individual Differences, 46, 557-561.

Grogan, S. (2016). Body image: understanding body dissatisfaction in men, women and children. New York: Taylor \& Francis.

Guo, S. (2016). A meta-analysis of the predictors of cyberbullying perpetration and victimization. Psychology in the Schools, 53, 432-453.

Harter, S. (2012). Self-perception profile for adolescents: manual and questionnaires. Denver: University of Denver.

Hinduja, S., \& Patchin, J. W. (2008). Cyberbullying: an exploratory analysis of factors related to offending and victimization. Deviant Behavior, 29, 129-156.

Hu, L. T., \& Bentler, P. M. (1999). Cutoff criteria for fit indexes in covariance structural analysis: conventional criteria versus new alternatives. Structural Equation Modeling, 6, 1-55.

Johnson, E. R., Affuso, O., Levitan, E. B., Carson, T. L., \& Baskin, M. L. (2019). Body image and dissatisfaction among rural Deep South African American women in a weight loss intervention. Journal of Health Psychology, 24, 1167-1177.

Joseph, S., Linley, P. A., Harwood, J., Lewis, C. A., \& McCollam, P. (2004). Rapid assessment of well-being: the Short Depression-Happiness Scale (SDHS). Psychology and Psychotherapy: Theory, Research and Practice, 77, 463-478.

Kircaburun, K., Demetrovics, Z., Király, O., \& Griffiths, M. D. (2018a). Childhood emotional trauma and cyberbullying perpetration among emerging adults: a multiple mediation model of the role of problematic social media use and psychopathology. International Journal of Mental Health and Addiction. https://oi. org/10.1007/s11469-018-9941-5.

Kircaburun, K., Jonason, P. K., \& Griffiths, M. D. (2018b). The Dark Tetrad traits and problematic social media use: the mediating role of cyberbullying and cyberstalking. Personality and Individual Differences, 135 , 264-269. 
Kircaburun, K., Griffiths, M. D., \& Billieux, J. (2019a). Childhood emotional maltreatment and problematic social media use among adolescents: the mediating role of body image dissatisfaction. International Journal of Mental Health and Addiction. https://doi.org/10.1007/s11469-019-0054-6.

Kircaburun, K., Griffiths, M. D., \& Billieux, J. (2019b). Psychosocial factors mediating the relationship between childhood emotional trauma and internet gaming disorder: a pilot study. European Journal of Psychotraumatology, 10, 1565031.

Kircaburun, K., Kokkinos, C. M., Demetrovics, Z., Király, O., Griffiths, M., \& Colak, T. S. (2019c). Problematic online behaviors among adolescents and emerging adults: associations between cyberbullying perpetration, problematic social media use and psychosocial factors. International Journal of Mental Health and Addiction, 17, 891-908.

Koronczai, B., Kökönyei, G., Urbán, R., Kun, B., Pápay, O., Nagygyörgy, K., et al. (2013). The mediating effect of self-esteem, depression and anxiety between satisfaction with body appearance and problematic internet use. American Journal of Drug and Alcohol Abuse, 39, 259-265.

Kowalski, R. M., Giumetti, G. W., Schroeder, A. N., \& Lattanner, M. R. (2014). Bullying in the digital age: a critical review and meta-analysis of cyberbullying research among youth. Psychological Bulletin, 140, 1073-1137.

Matz, P. E., Foster, G. D., Faith, M. S., \& Wadden, T. A. (2002). Correlates of body image dissatisfaction among overweight women seeking weight loss. Journal of Consulting and Clinical Psychology, 70, 1040-1044.

McVey, G., Tweed, S., \& Blackmore, E. (2004). Dieting among preadolescent and young adolescent females. Canadian Medical Association Journal, 170, 1559-1561.

Morken, I. S., Røysamb, E., Nilsen, W., \& Karevold, E. B. (2019). Body dissatisfaction and depressive symptoms on the threshold to adolescence: examining gender differences in depressive symptoms and the impact of social support. Journal of Early Adolescence, 39, 814-838.

Mura, G., Topcu, C., Erdur-Baker, O., \& Diamantini, D. (2011). An international study of cyber bullying perception and diffusion among adolescents. Procedia-Social and Behavioral Sciences, 15, 3805-3809.

Nolen-Hoeksema, S., \& Hilt, L. M. (2013). The emergence of gender differences in depression in adolescence. In Handbook of depression in adolescents (pp. 127-152). New York: Routledge.

Ozden, M. S., \& Icellioglu, S. (2014). The perception of cyberbullying and cybervictimization by university students in terms of their personality factors. Procedia-Social and Behavioral Sciences, 116, 4379-4383.

Patchin, J. W., \& Hinduja, S. (2015). Measuring cyberbullying: İmplications for research. Aggression and Violent Behavior, 23, 69-74.

Paxton, S. J., Neumark-Sztainer, D., Hannan, P. J., \& Eisenberg, M. E. (2006). Body dissatisfaction prospectively predicts depressive mood and low self-esteem in adolescent girls and boys. Journal of Clinical Child and Adolescent Psychology, 35, 539-549.

Salazar, L. R. (2017). Cyberbullying victimization as a predictor of cyberbullying perpetration, body image dissatisfaction, healthy eating and dieting behaviors, and life satisfaction. Journal of Interpersonal Violence. https://doi.org/10.1177/0886260517725737.

Schenk, A. M., Fremouw, W. J., \& Keelan, C. M. (2013). Characteristics of college cyberbullies. Computers in Human Behavior, 29, 2320-2327.

Shelton, S., \& Liljequist, L. (2002). Characteristics and behaviors associated with body image in male domestic violence offenders. Eating Behaviors, 3, 217-227.

Tokunaga, R. S. (2010). Following you home from school: a critical review and synthesis of research on cyberbullying victimization. Computers in Human Behavior, 26, 277-287.

Tosuntaș, Ș. B., Balta, S., Emirtekin, E., Kircaburun, K., \& Griffiths, M. D. (2018). Adolescents' eveningness chronotype and cyberbullying perpetration: the mediating role of depression-related aggression and anxiety-related aggression. Biological Rhythm Research. https://doi.org/10.1080 /09291016.2018.1513132.

Wilson, M., Viswanathan, B., Rousson, V., \& Bovet, P. (2013). Weight status, body image and bullying among adolescents in the Seychelles. International Journal of Environmental Research and Public Health, 10, $1763-1774$.

Zsila, Á., Orosz, G., Király, O., Urbán, R., Ujhelyi, A., Jármi, É., et al. (2018). Psychoactive substance use and problematic internet use as predictors of bullying and cyberbullying victimization. International Journal of Mental Health and Addiction, 16, 466-479.

Zych, İ., Baldry, A. C., Farrington, D. P., \& Llorent, V. J. (2019). Are children involved in cyberbullying low on empathy? A systematic review and meta-analysis of research on empathy versus different cyberbullying roles. Aggression and Violent Behavior, 45, 83-97.

Publisher's Note Springer Nature remains neutral with regard to jurisdictional claims in published maps and institutional affiliations. 


\section{Affiliations}

\section{Sabah Balta ${ }^{1} \cdot$ Emrah Emirtekin $^{2} \cdot$ Kagan Kircaburun ${ }^{3} \cdot$ Mark D. Griffiths $^{4,5}$}

1 School of Applied Sciences, Yaşar University, İzmir, Turkey

2 The Centre for Open and Distance Learning, Yaşar University, İzmir, Turkey

3 Faculty of Education, Duzce University, Duzce, Turkey

4 International Gaming Research Unit, Psychology Department, Nottingham Trent University, Nottingham, UK

5 Psychology Department, Nottingham Trent University, 50 Shakespeare Street, Nottingham NG1 4FQ, UK 